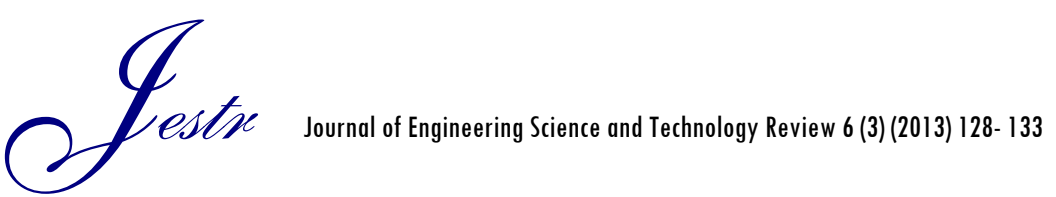

Research Article

\title{
The feasibility analysis of the performance of the phase change material wallboard used in Southwest China
}

\author{
Zhi-yong ZHOU ${ }^{1, *}$ and Ye-cong HE \\ ${ }^{I}$ Faculty of Civil Engineering and Mechanics, Kunming University of Science and Technology, Kunming, Yunnan province, \\ 650500, China \\ ${ }^{2}$ Faculty of Urban Construction and Environmental Engineering, Chongqing University, Chongqing, 400045, China
}

Received 10 June 2013; Accepted 23 November 2013

\begin{abstract}
In order to study the feasibility that PCM wallboard use in the building of Southwest China, based on the enthalpy model of the PCM wallboard, with a analysis of the factors effecting the heat transfer performance of PCM, taking Chongqing as an example to choose one suitable type of PCM wallboard for Southwest China, simulating the heat transfer performance of a PCM wallboard room and a common room in Chongqing, testing the indoor air temperatures of the PCM room and a common room in summer and winter for validating the simulation through field experiments and counting with a peak load shifting economy policy the analysis shows that such a PCM room is not only energy efficient, thermal comfort, and it also has a short investment period (only 12.4 months).
\end{abstract}

Keywords: Phase Change Material Wallboard Room, Building Energy Saving, Enthalpy Model, Heat Transfer

\section{Introduction}

Adopting the "Peak load shifting" policy contributes to a wide development prospects of the technology of thermal energy storage with phase change material. The research about the technology was started at the last century 80'. The Building Study Center of the Concordia University of Canada and the Florida Institute of Technology of America have researched the performance of fatty acid phase change material wallboard and how to reach the necessary heat storage by controlling the uptake and melting amount of PCM [1], [2]. The Kanagawa University and Tokyo University of Japan have research on the performance of organic phase change material wallboard and the thermal property of the PCM room. The research data shows PCM can make the heat load be more gentle, people feel more comfortable in the radiation region, the electricity consumption be reduced and it is helpful to cut down peak load [3]. Jiang Yi analyzed the present research situation of phase change and chemical energy storage applied to building heating and their study also point out the right research direction of this field [4]. Yu Dan has researched the performance of the phase change material composed of HR-35, HR-50 and lauric acid [5]. Feng Guohui put forward getting phase change wallboard surface heat transfer coefficient with genetic algorithm by studying the heat transfer performance of composite phase change material wallboard through experiments [6]. Lin Kun studied the heating performance of electro-thermal phase change material wallboard and analyzes the application effect of this system in winter in several climatic regions of China [7].

* E-mail address: zhiy_zhou@163.com

ISSN: 1791-2377 @ 2013 Kavala Institute of Technology. All rights reserved.
Zhang Yinping researched the PCM wallboard applied in Yiling in summer and the effect of the position of wallboard and insulation layer on whole room's heat comfortable [8].

Though simulating and analyzing some situations here this paper aim to determine the coefficient of the PCM wallboard suitable for Chongqing, research the performance of PCM wallboard room in winter and summer and get the economy analysis.

\section{The mathematical model of PCM wallboard}

\subsection{Analysis of the heat transfer of PCM wallboard}

The heat transfer process includes heat accumulation and release. In order to study the effect of the parameters of PCM wallboard on its heat transfer performance, it is heating by a homogeneous heat source $\left(a q_{0}\right)$ provided by electro-thermal film in the heat storage process. Then the temperature, thickness and radius for phase change were determined.

If $a=1$, the wallboard is accumulating. The energy was absorbed from $a q_{0}$. Meanwhile the heat is exchanging in the medial wall. The rate of heat through radiation heat transfer is defined as $q_{\text {inf }}$ and through the convective heat transfer as $q_{\text {ind }}$ According to the energy conservation principle, while $a q_{0}>q_{\text {inf }}+q_{\text {ind }}$, the heat storage rate of the PCM wallboard can be shown as:

$q_{\mathrm{c}}=a q_{0}-q_{\text {ind }}-q_{\text {inf }}$

where

$q_{\mathrm{c}}$ : heat storage rate $(\mathrm{W})$

$q_{0}$ : power in unit area $\left(\mathrm{W} / \mathrm{m}^{2}\right)$

$a q_{0}$ : homogeneous heat source $(\mathrm{W})$ 
$q_{\text {ind }}:$ convective heat transfer $(\mathrm{W})$

$q_{\text {inf: }}$ radiative heat transfer $(\mathrm{W})$

when $a=0$, the heat was released and the rate of it can be calculated as:

$q_{\mathrm{F}}=q_{\text {ind }}-q_{\text {inf }}$

where

$q_{\mathrm{F}}$ : heat release rate $(\mathrm{W})$

\subsection{Establishing mathematical model of the PCM} wallboard

In order to simplify the model, study the heat storage unit more deeply and stand out its physical essence, before the following step it is necessary to make some assumption, simplification and some essential premises.

(1) Ignore the natural convection as PCM melting and the under cooled effect as solidifying.

(2) Taking heat conduction as the main way of the heat transfer in PCM. Heat only transfers in thickness direction and the convective heat transfer of liquid phase will be overlooked.

(3) PCM is regarded as being pure and isotropic.

(4) The initial temperature was lower than the other phase change temperature. Assume that the volume of the wallboard wouldn't change.

(5) According to the one-dimensional heat transfer assumption, set up Axes ox from the medial side to the outside of the wallboard.

The enthalpy model [9] of the heat transfer of PCM wallboard is shown in Fig.1.

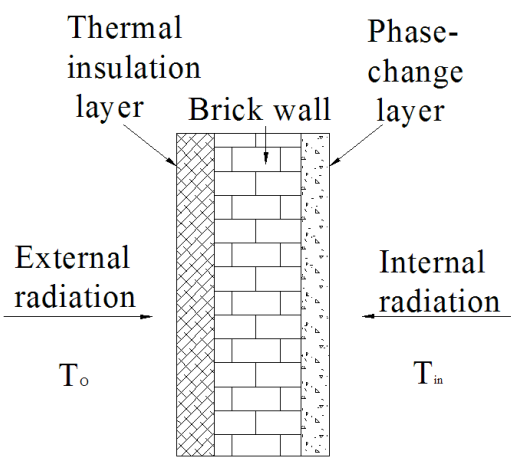

Fig. 1 One-dimensional phase change heat transfer panel diagram

Therefore, the related calculation can be expressed as:

$\rho_{i} \frac{\partial H}{\partial \tau}=\lambda_{i} \frac{\partial^{2} T}{\partial x^{2}}$

The boundary condition is shown as:

$$
\left\{\begin{array}{c}
q_{\text {ind }}+q_{\text {inf }}=\left.\lambda \frac{\partial T}{\partial X}\right|_{x=L} \\
q_{0}=-\left.\lambda \frac{\partial T}{\partial x}\right|_{x=0}
\end{array}\right.
$$

The radiation heat transfer rate in unit area $q_{\text {inf }}$ as: $q_{\text {inf }}=5.67\left[\left(\frac{T_{q i}}{100}\right)^{4}-\left(\frac{T_{f}}{100}\right)^{4}\right]$

where

$T_{\mathrm{qi}}$ : temperature of interior wall surface $\left({ }^{\circ} \mathrm{C}\right)$

$T_{\mathrm{f}}$ : average temperature of the non-radiative structure surface $\left(22^{\circ} \mathrm{C}\right)$

The $q_{\text {ind }}$ is calculated as:

$q_{\text {ind }}=1.78\left(t_{q i}-t_{\text {in }}\right)^{1.32}$

where

$t_{\text {in: }}:$ indoor temperature $\left(26^{\circ} \mathrm{C}\right)$

Relation between the temperature $(T)$ and enthalpy $(H)$ as:

$\left\{\begin{array}{cc}T=\frac{H}{c_{p s}} & H<H_{S} \\ T=\frac{H+\left(T_{m}-\varepsilon\right) Q_{p m} / 2 \varepsilon}{c_{p s}+\frac{Q_{p m} / 2 \varepsilon}{2 \varepsilon}} & H_{S} \leq H \leq H_{L} \\ T=T_{m}+\varepsilon+\frac{H-H_{L}}{c_{p l}} & H_{L}<H\end{array}\right.$

where

$H_{\mathrm{s}}$ : enthalpy of solid PCM $(\mathrm{J} / \mathrm{kg})$

$H_{\mathrm{L}}$ : enthalpy of liquid PCM $(\mathrm{J} / \mathrm{kg})$

$T_{\mathrm{m}}$ : average phase change temperature $(\mathrm{K})$

$Q_{\mathrm{pm}}$ : phase change latent heat of PCM $(\mathrm{kJ} / \mathrm{kg})$

$H_{\mathrm{L}}$ can ben expressed as:

$H_{L}=c_{P s}\left(T_{m}+\varepsilon\right)+Q_{p m}$

Then, $q_{0}$ can be calculated: $q_{0}=20 /(0.32 \times 0.43)=145\left(\mathrm{~W} / \mathrm{m}^{2}\right)$.

It can be controlled by low temperature radiation electrothermal film (DYMSCO, made in Korea) with power $20 \mathrm{w} /$ piece and size $320 \times 430 \times 0.24\left(\mathrm{~mm}^{3}\right)$. Phase change latent heat $Q_{p m}$ is displayed as follow.

The $Q$ was as listed below, it is calculated as:

$Q_{p m}=Q \frac{\partial f_{s}}{\partial \tau}$

where

$f_{\mathrm{s}}$ : phase change rate

The phase change rate, taking the heating process as an example, is as follow. In addition when the PCM is solidifying to release heat, the description of $f_{s}$ is just the opposite as:

$f_{S}=\left\{\begin{array}{cc}0 & T<T_{S} \\ f(T) & T_{S} \leq T \leq T_{L} \\ 1 & T_{L}<T\end{array}\right.$

Phase change rate have relations with pre and post temperature at an interval. In the formulae as follow, the superscript 1 and 0 stand for the previous time and the next time respectively. Utilizing two temperature values to judge 
the phase change rate, it can be simplified by iterative computation as:

$$
f_{s}^{0}=\left\{\begin{array}{cc}
0 & T^{0}<T_{S} \\
f\left(T^{0}\right) & T_{S} \leq T^{0} \leq T_{L} \\
1 & T_{L}<T^{0}
\end{array}\right.
$$

or

$$
f_{S}^{1}=\left\{\begin{array}{cc}
0 & T^{1}<T_{S} \\
f\left(T^{1}\right) & T_{S} \leq T^{1} \leq T_{L} \\
1 & T_{L}<T^{1}
\end{array}\right.
$$

So the above equations can be calculated as:

$$
Q_{p m}=Q \frac{f_{S}^{1}-f_{S}^{0}}{\Delta \tau}
$$

\subsection{Heat transfer model of phase change wall room}

There are four equations the heat transfer of the room satisfied.

(1) The Outer surface of exterior wall:

Conductive heat + convective heat exchange with the air outdoor + solar radiation heat exchange + surface radiation heat exchange + diffuse sky radiation heat $=0$.

(2) The inner surface of the exterior wall:

Conductive heat transfer + convective heat exchange + radiation heat transfer $=0$.

(3) Windows:

$Q_{C}=$ conductive heat transfer from the window into the room + solar radiation heat transfer from the window into the room + the heat convective heat exchange of the surface of the window + the radiation heat transfer of the window's surface.

(4)The heat balance formula of the room is calculated as:

$c_{p} \rho V \frac{d t}{d \tau}=\sum Q_{d}+Q_{R}+Q_{C}$

where

$Q_{\mathrm{d}}$ : convective heat transfer rate of the inner surface of enclosure structure $(\mathrm{W})$

$Q_{\mathrm{r}}$ : radiative heat transfer rate of the inner surface of enclosure structure (W)

$Q_{\mathrm{c}}$ : heat transfer rate through the windows into the interior including the ventilation heat transfer at night (W)

\section{Numerical solution for the temperature field of PCM wallborad}

Based on the differential equations and the relative boundary conditions stated above, adopting finite difference method to discrete the partial differential equation of phase change heat transfer and full implicit method for time, center difference for x-coordinate, it can be drawn to approximate numbers of the temperature and heat flux of each specific part of each specific time of PCM wallboard. Net divided for PCM wallboard calculation as Fig2.

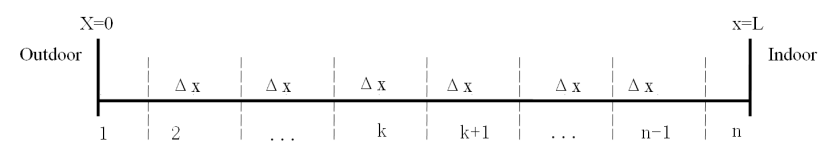

Fig. 2 The numerations of the PCM wallboard
Time-step is 20 minutes. Space-step is determined by dimensionless number. For obtaining a relative stable solution, the two numbers must be limited. So assume that $F_{0} \leq 0.5, B_{\mathrm{i}} \leq 0.1$.

For simplifying and keeping precision when dealing with the model [10]:

$F o=\frac{k \Delta \tau}{\rho c_{p}(\Delta x)^{2}}$

and

$B i=\frac{h \Delta x}{k}$

where

$F_{\mathrm{o}}$ : Fourier number

$B_{\mathrm{i}}$ : Biot number

The climate information was obtained from "China building thermal environment analysis special purpose climate date", including sky temperature, the direct sunlight radiation intensity, sky scattering intensity, land surface temperature, wind speed [11]. Solving the equations above with the software Matlab the value of the room's temperature time by time. For verifying the correctness of the program, the enthalpy model [12] should be solving firstly. If the result is in $6 \%$ of the allowable date error range, the program is right.

\section{Analysis of the simulation results}

The PCM wallboard is made up by paraffin and high density polyethylene in certain proportions. Meanwhile, for improving the heat conduction coefficient, it was added some graphite in proper proportion. The physics parameters is as listed: density $950 \mathrm{~kg} / \mathrm{m}^{3}$, specific heat $2.85 \mathrm{~kJ} /(\mathrm{kg} \mathrm{K})$, enthalpy $200 \mathrm{~kJ} / \mathrm{kg}$, heat conduction coefficient $0.40 \mathrm{~W} /$ $\left(\mathrm{m} \cdot{ }^{\circ} \mathrm{C}\right)$. The heat transfer process was simulated on condition of different thickness of PCM wallboard, phase change radius, phase change temperature and dimensionless number. The law of the effect from parameters change on the temperature of PCM wallboard was analyzed to choose a suitable type of PCM wallboard.

4.1 Influence from phase change temperature on the performance of wallboard's heat transfer

Varying average phase change temperature $T_{m}$, the heat transfer model testing data are listed in Table $1 .\left(\varepsilon=2^{\circ} \mathrm{C}\right.$, $t_{i n}=24^{\circ} \mathrm{C}, L=0.06 \mathrm{~m}, F o=0.4, B i=0.1$ )

Table 1 Data of the PCM wallboard with different $T_{\mathrm{m}}$

\begin{tabular}{c|c|c|c|c}
\hline Parameters $\left(T_{m}\right)$ & 29 & 31 & 33 \\
\hline Endothermic time & $\mathrm{h}$ & 11.44 & 11.05 & 10.44 \\
\hline Delay time & $\mathrm{h}$ & 12.11 & 7.59 & 5.38 \\
\hline Outer surface temperature & Minimum & 28.35 & 30.97 & 33.57 \\
\hline Outer surface temperature & Maximum & 43.03 & 45.58 & 48.12 \\
\hline Inner surface temperature & Minimum & 24.94 & 25.95 & 26.95 \\
\hline Inner surface temperature & Maximum & 25.90 & 26.88 & 27.85 \\
\hline
\end{tabular}

As was shown in Table 1, as average phase change temperature become higher, the endothermic time was cut down slightly, beside that the temperature of inner and outer face are higher, but the delay time was cut down substantially. Therefore it is concluded that the average phase change temperature mainly effect the delay time.

4.2 Influence from the thickness of phase change wallboard on the performance of heat transfer 
Varying the thickness of PCM wallboard $L$, the data is listed in Table 2. $\left(T_{m}=32^{\circ} \mathrm{C}, \varepsilon=2{ }^{\circ} \mathrm{C}, t_{i n}=24^{\circ} \mathrm{C}, F O=0.4, B i=0.1\right)$

The data of Table 2 shows while the wallboard is thicker, the endothermic time increases but slightly, even as the $\mathrm{L}$ increases almost twice, the endothermic time just increases less than 1.5 hours, but the delay time become more longer. It is very good at the time electricity peak value can be dropped down well in summer. However the delay time increment will make the exothermic time longer during the day. But it can be done by venting at night to release the heat. The reason why the wallboard is thicker the outer surface's temperature is higher is that when the heat storage capacity of PCM wallboard become stronger, it spend more time to heat, so the temperature relative to the outer surface of wallboard increase substantially. Meanwhile the temperature of inner surface change slightly and the limited temperature change less than $1{ }^{\circ} \mathrm{C}$ because the $\mathrm{L}$ and thermal resistance become lager. So it mostly effects on delay time and improves the heat storage performance but does nothing to the comfort of the room.

Table 2 Data of the PCM wallboard with different $L$

\begin{tabular}{c|c|c|c|c}
\hline \multicolumn{2}{c}{ Parameters $(L)$} & 0.05 & 0.07 & 0.09 \\
\hline Endothermic time & $\mathrm{h}$ & 10.30 & 11.11 & 11.40 \\
\hline Delay time & $\mathrm{h}$ & 4.73 & 8.09 & 12.42 \\
\hline Outer surface temperature & Minimum & 32.08 & 32.44 & 32.71 \\
\hline Outer surface temperature & Maximum & 45.13 & 48.47 & 51.32 \\
\hline Inner surface temperature & Minimum & 26.75 & 26.19 & 25.78 \\
\hline Inner surface temperature & Maximum & 27.87 & 26.95 & 26.30 \\
\hline
\end{tabular}

4.3 Influence from phase change radius on the performance of heat transfer

The heat transfer model was simulated with varying $\varepsilon$ with $1.5^{\circ} \mathrm{C}, 2^{\circ} \mathrm{C}$ and $2.5^{\circ} \mathrm{C}$. The results were shown in Table 3 .

Table 3 Data of the PCM wallboard with different $\varepsilon$

\begin{tabular}{c|c|c|c|c}
\hline \multicolumn{2}{c|}{ Parameters $(\varepsilon)$} & 1.5 & 2 & 2.5 \\
\hline Endothermic time & $\mathrm{h}$ & 6.80 & 10.76 & 13.44 \\
\hline Delay time & $\mathrm{h}$ & 5.58 & 6.29 & 6.86 \\
\hline Outer surface temperature & Minimum & 32.84 & 32.28 & 31.64 \\
\hline Outer surface temperature & Maximum & 45.89 & 46.86 & 47.71 \\
\hline Inner surface temperature & Minimum & 26.74 & 26.45 & 26.19 \\
\hline Inner surface temperature & Maximum & 27.21 & 27.36 & 27.53 \\
\hline
\end{tabular}

Table 3 shows that with $\varepsilon$ increases, the endothermic time and delay time increases. But the change rage of delay time is slight. Besides, the maximum of inner and outer surface temperature is higher and the minimum is lower contrarily. So the change rage of the temperature is bigger. The reason of stated above is that when the radius $\varepsilon$ was changed, in other word the temperature of phase change was changed, the capacity of the wallboard's heat storage was changed, that means the endothermic time was changed. Therefore the main changing object is the endothermic time and the influence on inner and outer surface temperature can be neglected.

\subsection{The determination of the PCM wallboard}

According the actual situation, the PCM wallboard must meet conditions: the max temperature can be not over $60^{\circ} \mathrm{C}$, the surface radiation intensity is between $30 \sim 60 \mathrm{~W} / \mathrm{m}^{2}$, make sure that the heating time in winter must be during the low valley electricity price time (23:00 7:00), in other words, between 8 hours. So the delay time is just over at the heating time start. A perfect period of the endothermic and exothermic time should be not over 24 hours. On the other hand the phase change temperature must be in an appropriate range as it was used in summer to adjust the peak of electricity. The requirement of delay time is different according to the type of the room. This one stated is an office, the working hours is 8:00 17:00, by reason of the top temperature of outdoor air comes at 12:00 14:00, the delay time should be in $6 \sim 8$ hours. At last, the parameters are fixed according to local climate.

The required $L$ and $T_{m}$ are determined according to the changing rule of phase change radius, average phase change temperature, the thickness of PCM wallboard, endothermic time, delay time and the surface temperature analyzed above. Where parameters of Chongqing is as: $\varepsilon=1{ }^{\circ} \mathrm{C}, T_{m}=30^{\circ} \mathrm{C}, L$ $=0.04 \mathrm{~m}, F_{O}=0.4, B i=0.1$. So endothermic time is 6.5 hours, the delay time is 6.23 hours, the minimum of inner surface temperature is $25.96^{\circ} \mathrm{C}$, and the maximum is $26.64^{\circ} \mathrm{C}$, the minimum of inner surface heat flux is $25.00 \mathrm{~W} / \mathrm{m}^{2}$ and the maximum is $30.70 \mathrm{~W} / \mathrm{m}^{2}$. The requirement is satisfied.

\section{Analysis of PCM wallboard simulation}

Taking Chongqing as the example, the electricity through period starts at 23:00 was analyzed. The indoor air hourly temperature of PCM and the commons in two days standing for winter and summer was chosen to be simulated respectively, to research the dynamic heat transfer property of the two rooms and to evaluate the feasibility and economic efficiency of the plan. The climate data came from "China construction thermal environment analysis special climate data".

\subsection{PCM wallboard room's heat transfer simulation and analysis}

For research the room's indoor temperature changes in summer, where the parameters equal which stated above. The simulation time was $5^{\text {th }}$ August. The same climate situation was chosen for the contrast between the PCM room and the commons' hourly temperature. Parameters to be test in the simulation are PCM indoor temperature $t_{p}$ and common room indoor temperature $t_{n}$. The result was shown in Fig.3.

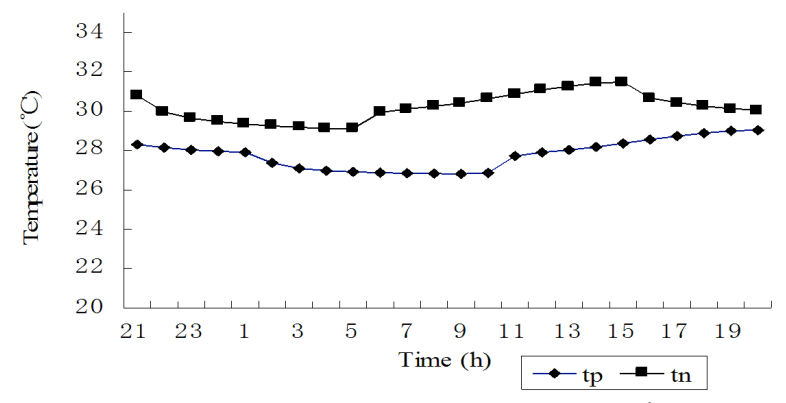

Fig. 3 Temperature of PCM room and common room on $5^{\text {th }}$ August

The two temperature lines in Fig.3 go with a similar tendency. The $t_{n}$ is about $4^{\circ} \mathrm{C}$ higher than $t_{p}$. But there is 5 hours delay time of $t_{p}$ which can delay the highest temperature well. As shown in Fig.3, the common room's temperature was changing between $29^{\circ} \mathrm{C} \sim 33^{\circ} \mathrm{C}$ and the amplitude is about $4^{\circ} \mathrm{C}$. The temperature $t_{p}$ stayed between $26^{\circ} \mathrm{C} \sim 28^{\circ} \mathrm{C}$ and just has a $2^{\circ} \mathrm{C}$ amplitude. So it is better to people. While thinking about the heat storage property of PCM, the simulation process was assumed that a constant chilling input in non-office time to remove the heat released at night. 


\subsection{Heat transfer simulation of PCM wallboard room in} winter

Based on the same parameters above, the PCM heat transfer process was simulated for winter situation at $1^{\text {th }}$ January. The parameters to be tested are $t_{\mathrm{n}}$, PCM wallboard's heating side temperature $t_{p 1}$ and inner side temperature $t_{p 2}$. (Shown in Fig.4)

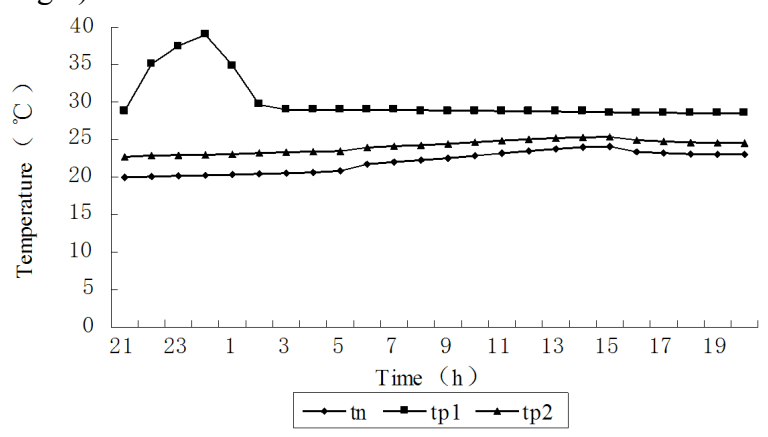

Fig. 4 Temperatures of PCM wallboard and the room on $19^{\text {th }}$ January

As shown in Fig.4, the heating side of the wallboard's highest temperature was less than $40^{\circ} \mathrm{C}$ and in the safe range. The heating time is 6.5 hours. When it was the electricity through time, the inner temperature of the wallboard was changing between $23 \sim 25^{\circ} \mathrm{C}$ and the indoor temperature of is between $20 \sim 23^{\circ} \mathrm{C}$.

\subsection{Contrast between PCM wallboard room and common} room in winter climate

With the same climate situation simulating the heat transfer process of PCM wallboard room and the commons both at 19th January, the temperature changing lines are shown in Fig.5.

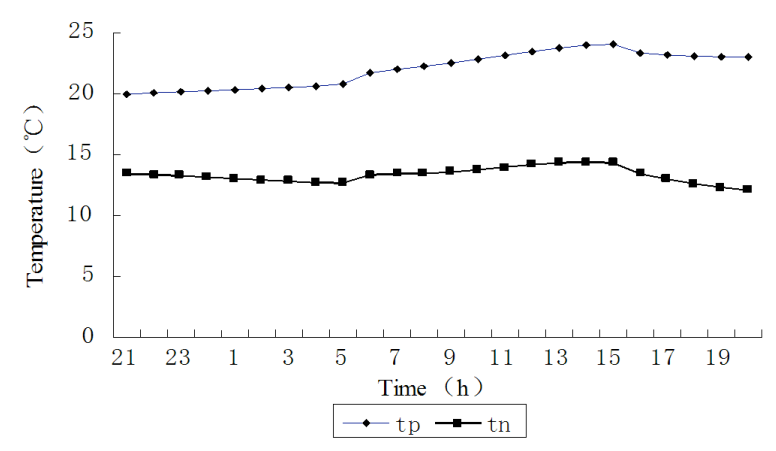

Fig. 5 Temperature of PCM room and common room on $19^{\text {th }}$ January

As shown is Fig.5, the temperature of the two types room has a large disparity. So taking advantage of PCM has a little higher indoor temperature than the standard but more suitable for living. It is no reason to reduce the thickness of the wallboard because the technology was mostly used to shave peak in hot summer and cold winter. Therefore the indoor temperature was only controlled by heating time. Besides, the internal disturbance of the simulation was assumed $300 \mathrm{~W}$. So the heating time can be controlled according to the indoor devises' working condition flexibly.

\section{Analysis of the experiments}

To prove the correctness of the calculation, under the same condition as the simulation, the common room was tested every other hour for 72 hours uninterruptedly at $4^{\text {th }}, 5^{\text {th }}$ and $6^{\text {th }}$ August. Considering the chill input in simulation at night, so there is only the temperature situation at daytime. The result is shown as Fig.6.
As is shown in Fig.6, $t_{n c}$ is between $32 \sim 35^{\circ} \mathrm{C}, t_{n m}$ is between $31 \sim 33^{\circ} \mathrm{C}, t_{p c}$ is between $27 \sim 30^{\circ} \mathrm{C}$ and $t_{p m}$ is between $26 \sim 28^{\circ} \mathrm{C}$. All of them increase during 10:00 and 14:00 because from 10:00 the solar radiation intensity begins to increase gradually. So the room gets more thermal. Until 14:00 the temperature reaches the highest value and the heat exchange between indoor and outdoor increase. So there are two times low-amplitude increments. The testing temperature is higher than the simulating temperature due to the climate data from "China construction thermal environment analysis special climate data" based on the climate in 1971-2003. Considering the highest temperature of a hundred year in 2007 and it's about $3^{\circ} \mathrm{C}$ higher than the same time in history, the simulation is correct.

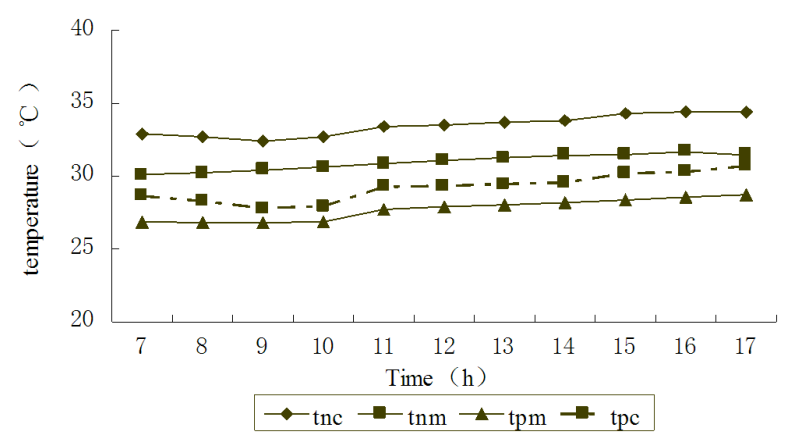

Fig. 6. Temperature of PCM room and common room on $5^{\text {th }}$ August (The letter $n$ represents for common room, $p$ represents for PCM wallboard room and $\mathrm{c}$ is test value and $\mathrm{m}$ represents for simulating value)

Above all, under the no air conditioning situation, the indoor temperature can reaches $26^{\circ} \mathrm{C} \sim 28^{\circ} \mathrm{C}$ in summer. On the other hand, at the low electricity through taking 6.5 hours heating to electro-thermal film in winter, the indoor temperature can reach $20 \sim 23{ }^{\circ} \mathrm{C}$. It can both meet the comfort requirement in summer and winter. As it was shown above the testing temperature is in accord with simulating temperature

\section{Economical efficiency analysis}

Assuming the air conditioning of common room is Green (KFR-32GW/K(32516)E-HN5), the electro-thermal film is DYMSCO (made in Korea) and the PCM's working time is both three month in summer and winter, the economic efficiency analysis is shown as Table 4.

Table 4 Price of the PCM and electricity

\begin{tabular}{c|c}
\hline Material or Period of use power & Price \\
PDPE & $8360($ Yuan $/ \mathrm{t})$ \\
Electrothermal film & $5920(\mathrm{Yuan} / \mathrm{t})$ \\
Air conditioning & $158\left(\mathrm{Yuan} / \mathrm{m}^{2}\right)$ \\
Flat electricity price in the dry season & $0.927(\mathrm{Yuan} / \mathrm{kWh})$ \\
Valley electricity price in the dry season & $0.464(\mathrm{Yuan} / \mathrm{kWh})$ \\
Peak electricity price in the dry season & $1.391(\mathrm{Yuan} / \mathrm{kWh})$ \\
Valley electricity price in the wet season & $0.379(\mathrm{Yuan} /(\mathrm{kWh})$ \\
Peak electricity price in the wet season & $1.138(\mathrm{Yuan} / \mathrm{kWh})$ \\
Flat electricity price in the wet season & $0.759(\mathrm{Yuan} / \mathrm{kWh})$ \\
\hline
\end{tabular}

The commercial electricity price of Chongqing is 0.843 (Yuan $/ \mathrm{kWh}$ ) if below $1 \mathrm{kV}$. The wet season is from June to 
October, the dry season is from December to January of next year and the normal season is May and November.

PCM wallboard's price estimation: the material of the wallboard is made up with HDPE and paraffin (price of Fushun Petrochemical Corporation, January 2009) at some rate. Element graphite was added for improving thermal conductivity [13]. So the costs of $0.04 \mathrm{~mm}$ thick wallboard are calculated as:

$0.04 \times 1 \times 0.915 \times(1 \times 8360+3 \times 5920) \div 4=238.998\left(\right.$ Yuan $\left./ \mathrm{m}^{2}\right)$

Assuming the processing charge is $10 \mathrm{Yuan} / \mathrm{h}$, the wallboard costs about $¥ 248.998$. The primary investment equals $248.998 \times 15=3734.97 ¥$. Besides that the electrothermal film costs $158 \times 15=2370 ¥$. So the total costs is $6104.97 ¥$. Electricity price was calculated as:

$Y=y \times h \times p \times t \times m \div \phi$

The electricity costs for PCM wallboard heating in winter can be calculated from the above formulae:

$0.464 \times 6.5 \times 3.5 \times 30 \times 3 / 0.9=1055.6 ¥$.

The electricity costs for common room in summer and winter: $(0.927+1.391+0.759+1.138) \times 5 \times 3.5 \times 30 \times 3=5063.6 ¥$

So the investment recovery period $n=(6104.97-2650)$ $\times 1.2 /(5063.6-1055.6)=12.4 ¥$.
According to the stated above, it only costs about one year to recover the investment. More than that, it could largely relieve the stress of the electric network. So it is feasible and will bring huge economic benefits to the hot summer and cold winter area.

\section{Economical efficiency analysis}

According to the second law of thermodynamics, electric heating is not a scientific heating way. But the power cannot storage directly and the generated energy will not be change in peak or trough period. So it would be huge waste if the trough electricity is not used. As was stated above, trough energy storage to supply energy for the next day in winter will be a good way of peak load shifting. On the other hand, directly take advantage of the heat storage property delay time to avoid the electricity peak in summer. There are huge economic benefits with supplying a comfortable environment and higher trough electrical energy efficiency.

\section{Acknowledgements}

This work was financially supported by:

(1) National Natural Science Foundation of China, under Grant No.51268020.

(2) Applied Basic Research Program Foundation of Yunnan Province, under Grant No. 2011FZ024.

\section{References}

1. Feldman, D., Banu, D., Hawers, D., "Obtaining an energy storing building material by direct incorporation of an organic phase change material in gypsum wallboard", Solar Energy Materials, 22(2), 1991, pp. 231-242.

2. Rudd, A. F., "Phase-change material wallboard for distributed thermal storage in building", ASHRAE Transactions 99(2), 1993, pp. 339-346.

3. Takeshi, Kondo., Tadahiko, Ibamoto., Tsubota, Yuuji., "Research on the thermal storage of PCM wallboard", Japan Architectural planning environment engineering, 540, 2001, pp. 23-29.

4. Zhang, Y.-P., Kang, Y.-B., Jiang, Y., "Research of phase change and chemical energy storage using in building heating field", Heating Ventilation \& Air Conditioning, 29(5), 1999, pp. 34-37.

5. Yu, D., Cao Y., Mei, F.-M., "Combined PCM heat interchanger energy storage rate experiment and research", Heating Ventilation \& Air Conditioning, 38(5), 2008, pp. 65-67.

6. Feng, G.-H., Gao F.-S., Fu, Y.-H, "Complex PCM wall thermal property experiment and parameters distinguishing methods", Journal of Shengyang Architecture and Civil Engineering University (natural sciences), 20(3), 2004, pp. 207-210.
7. Lin, K.-P., Zhang Y.-P., "Electrothermal PCM heat storage floor thermal performance simulation", Acta Energiae Solaris Sinica, 5, 2003, pp.633-637. Lin, K.-P., Zhang Y.-P., "Electrothermal PCM heat storage floor thermal performance simulation", Acta Energiae Solaris Sinica, 24(5), 2003, pp.633-637.

8. Lin, K.-P., Zhang Y.-P., Jiang, Y., "Summer air conditioning PCM wall design". Acta Energiae Solaris Sinica, 24(2), 2003, pp. 145151.

9. Voller, V., Cross, M., “Accurate solutions of moving boundary problems using the enthalpy method", Int J Heat Mass Transfer, 24(3), 1981, pp.545-556.

10. Yan, Q.-S., Zhao Q.-Z., "Building heating process analysis". China Architecture \& Building Press, Beijing, 1986.

11. National Meteorological Information Centre Reference Room., "China building thermal environment analysis special climate data", China Architecture \& Building Press, Beijing, 2005.

12. Shamsundar, N., Sparrow E. M., "Analysis of Multidimensional Conduction Phase Change Via the Enthalpy Model", Journal of Heat Transfer, 97(3), 1975, pp. 333-340.

13. Zhang, Y.-P., Ding J.-H., "Influence of additives on the thermal conductivity of shape-stabilized phase change material", Solar energy materials and solar cells, 90(11), 2006, pp. 1692-1702. 